\title{
Naturaleza, tráfico y registro del derecho de emisión de gases de efecto invernadero
}

\author{
Victor Manteca Valdelande \\ Doctor en Derecho
}

\section{INTRODUCCIÓN}

Una de los instrumentos jurídicos de la Convención Marco de Naciones Unidas sobre cambio climático de 2002 es el Protocolo de Kyoto que obliga a cumplir a los signatarios una serie de compromisos sobre reducción de gases efecto invernadero y cuya ratificación dio un notable impulso al Programa Europeo de Cambio Climático con la entrada en vigor de la Directiva 2003/87/CE del Parlamento Europeo y del Consejo que estableció un régimen de comercio de derechos de emisión de este tipo de gases, en la Unión Europea, inspirado en uno de los instrumentos de mercado previstos en el Protocolo de Kyoto denominados mecanismos de flexibilidad. Por su parte el Reglamento comunitario de la Comisión relativo a un sistema normalizado y garantizado de registros ${ }^{1}$ estableció disposiciones y requisitos para garantizar el establecimiento de sistemas registrales de estos derechos y su tráfico. Todo ello ha dado lugar a que en el ordenamiento interno español se hayan aprobado dos normas relacionadas con esta materia, por un lado la Ley $1 / 2005^{2}$ regula la emisión a la atmósfera de gases de efecto invernadero a partir de fuentes situadas en una instalación sirviendo de instrumento legal para transponer la citada Directiva comunitaria y regulando el régimen de comercio de derechos de emisión de gases en el mercado español teniendo como objetivo final la reducción de emisiones; por otro lado el Real Decreto 1264/2005 ha

\footnotetext{
${ }^{1}$ Reglamento (CE) 2216/2004 de la Comisión de 21 de diciembre de 2004 relativo a un sistema normalizado y garantizado de registros de conformidad con la directiva 2003/87/CE del Parlamento Europeo y del Consejo y la Decisión no 280/2004/CE del Parlamento Europeo y del Consejo. (DOUE L386 29.12.2004).

${ }^{2}$ Ley $1 / 2005$ de 9 de marzo por la que se regula el régimen de comercio de derechos de emisión de gases de efecto invernadero (BOE núm. 59 de 10.3.2005).
} 
establecido el Registro nacional de Derechos de emisión (RENADE) regulando su organización administrativa y funcionamiento ${ }^{3}$.

En el presente trabajo se examina la naturaleza y régimen de los derechos de emisión así como las operaciones que conllevan su tráfico, así como los sistemas administrativos y registrales establecidos para reconocer los derechos y operaciones de transmisión.

\section{TEORÍA SOBRE LOS DERECHOS DE EMISIÓN}

El derecho de emisión regulado en la Ley 1/2005 puede definirse como el derecho subjetivo a emitir, durante un periodo de terminado y desde una instalación incluida en el ámbito de aplicación de la Ley, una tonelada equivalente de dióxido de carbono,

La titularidad originaria de la totalidad de los derechos de emisión que figuren en cada Plan Nacional de Asignación ${ }^{4}$.

Cada derecho de emisión solo es válido para el periodo de vigencia de cada Plan nacional de asignación, además el derecho de emisión es transmisible y la expedición, titularidad, transferencia, transmisión, entrega y cancelación de los derechos de emisión debe ser objeto de inscripción en el Renade.

El derecho de emisión puede tener origen en:

a) El Plan nacional de asignación de España.

b) Un Plan nacional de asignación de otro Estado miembro de la Unión Europea.

c) Un tercer país con compromiso de reducción o limitación de emisiones que sea parte del Protocolo de Kyoto, siempre que haya un previo reconocimiento en un instrumento internacional.

${ }^{3}$ BOE núm. 253 de 22.10.2005.

${ }^{4}$ Así como los derechos de emisión que formen parte de la reserva para nuevos entrantes, corresponde a la Administración General del Estado que los asignará o enajenará o cancelará de conformidad con lo establecido en la ley. 
d) Una reducción certificada de emisión ${ }^{5}$.

Con todo, los derechos de emisión son susceptibles de transmisión tanto entre personas físicas o jurídicas, en la Unión Europea, como entre éstas y otras personas físicas o jurídicas de terceros Estados, previo reconocimiento mutuo de los derechos de las partes firmantes en virtud de un acuerdo internacional ${ }^{6}$.

La adquisición de derechos de emisión, por una persona física o jurídica que no tenga la condición de titular de la instalación, requiere la previa apertura de una cuenta de haberes en el Registro nacional de derechos de emisión (Renade) y, además, los derechos de emisión solo pueden ser objeto de transmisión por parte de su titular una vez expedidos y transferidos a su cuenta de haberes ${ }^{7}$.

\section{AUTORIZACIÓN DE EMISIÓN}

Cualquier instalación en la que se desarrolle una actividad que genere las emisiones de dióxido de carbono que enumera la propia ley debe contar con autorización de emisión de gases de efecto invernadero expedida a favor de su titular ${ }^{8}$.

\footnotetext{
${ }^{5} \mathrm{O}$ bien una unidad de reducción de emisiones procedentes de los mecanismos de desarrollo limpio o de aplicación conjunta que sea expedida de conformidad con loo establecido en el Convenio marco de Naciones Unidas sobre cambio climático, el protocolo de Kyoto y su normativa de desarrollo y sea reconocida a los efectos de cumplir con la obligación de entrega de derechos en función de las emisiones emitidas durante el último año (art. 4.2 f) de la Ley 1/2005).

El reconocimiento podrá tener lugar siempre que:

- No hayan sido generadas por instalaciones nucleares.

- No hayan sido generadas por actividades de uso de la tierra, cambio de uso de la tierra o selvicultura.

- En el caso de proceder de proyectos de producción de energía hidroeléctrica con capacidad superior a los $20 \mathrm{MW}$, que dichos proyectos sean conformes con los criterios y directrices pertinentes aprobados por la Comisión Mundial de Presas.

${ }^{6}$ La Ley se refiere con un concepto más amplio a instrumento internacional.

${ }^{7}$ De conformidad a lo establecido en el artículo 26 de la Ley.

${ }^{8}$ El anexo I de la Ley 1/2005 establece que no deben incluirse las instalaciones cuya dedicación principal sea la investigación, desarrollo y experimentación de nuevos productos y procesos.

Los valores umbral se refieren, en general, a la capacidad de producción o a la producción. Si un mismo titular realizara varias actividades de la misma categoría en la misma instalación o emplazamiento, se sumarán las capacidades de dichas actividades.
} 
Cada autorización de emisión de gases de efecto invernadero, puede cubrir una o más instalaciones siempre que éstas se ubiquen en un mismo emplazamiento, guarde una relación de índole técnica y cuenten con un mismo titular.

Además la autorización de emisión también puede otorgarse a una agrupación de instalaciones que cumplan los requisitos que exige la propia ley.

\section{a) Autorización de instalación individual}

Las autorizaciones de emisión de gases de efecto invernadero de una instalación deben contener los siguientes elementos:

- Nombre y dirección del titular de la instalación.

- Identificación y domicilio de la instalación.

- Una descripción básica de las actividades y emisión de la instalación.

- Las obligaciones de seguimiento y notificación a la administración de emisiones de gases de efecto invernadero.

- La obligación de entregar, en los cuatro meses siguientes a cada año derechos de emisión en cantidad equivalente a las emisiones totales verificadas de la instalación durante el año anterior.

- Fecha prevista de entrada en funcionamiento.

Se incluyen las actividades siguientes:

- Actividades energéticas.

- Instalaciones de combustión con potencia superior a 20 MW. Quedando excluidas las de residuos peligrosos y urbanos.

- Refinerías de hidrocarburos.

- Coquerías.

- Producción y transformación de metales férreos

- Instalaciones de calcinación o sintetización de minerales metálicos.

- Instalaciones de producción de arrabio o de acero.

- Industrias minerales.

- Instalaciones de fabricación de cemento en hornos rotatorios con producción superior a 500 tons./día o de cal en hornos rotatorios con producción superior a 50 tons/día.

- Instalaciones de fabricación de vidrio incluida fibra con con capacidad de fusión superior a 20 tons/día.

- Instalaciones de productos cerámicos mediante horneado con capacidad de producción superior a 75 tons./día.

- Otras actividades

- Instalaciones industriales para fabricación de pasta de papel y cartón con capacidad de producción superior a 20 tons./día. 
Puede solicitar esta autorización el titular de la instalación que puede ser cualquier persona física o jurídica que opere o controle la instalación bien en condición de propietario, bien al amparo de cualquier otro título jurídico, siempre que éste le otorgue poderes suficientes sobre el funcionamiento técnico y económico de la instalación. Con respecto al concepto legal de ésta la Ley señala que tienen esta condición cualquier unidad técnica fija donde se lleven a cabo una o varias actividades contempladas en la Ley 1/2005 productoras de emisión de gases de efecto invernadero, así como las actividades directamente relacionadas con aquellas que guarden una relación de índole técnica con las actividades realizadas en dicho lugar y puedan tener repercusiones sobre las emisiones y la contaminación

Para obtener dicha autorización, el titular de la instalación debe dirigir su solicitud al órgano autonómico competente en cuyo territorio se ubique la instalación.

Toda solicitud de autorización debe contener documentación aneja con la siguiente información:

- La identificación y acreditación del titular.

- Identificación y domicilio de la instalación.

- Descripción de la instalación, sus actividades y de la tecnología utilizada.

- Las materias primas auxiliares empleadas cuyo uso puede producir emisión de gases de efecto invernadero.

- Fuentes de emisión existentes en la instalación.

- Medidas previstas para llevara cabo el seguimiento y notificación de emisiones.

Además a la solicitud debe acompañarse un resumen explicativo de las medidas especificadas.

La autorización de emisión de gases de efecto invernadero se otorga siempre y cuando el organismo autonómico competente por razón del domicilio de la instalación considere que queda suficiente acreditado que el titular de la instalación es capaz de garantizar el seguimiento y notificación de las emisiones con arreglo a lo que exige la Ley $1 / 2005^{9}$. Transcurrido el plazo de

\footnotetext{
${ }^{9}$ Art. 4.2, párrafos d) y e).
} 
tres meses sin haberse notificado resolución expresa, el interesado puede entender desestimada la solicitud por silencio administrativo ${ }^{10}$.

Además, el titular de la instalación debe informar al órgano competente de cualquier proyecto de cambio en el carácter, funcionamiento o el tamaño de la instalación, así como de todo el cambio que afecte a la identidad o al domicilio del titular, además el propio órgano deberá modificar de oficio el contenido de la autorización, en el plazo máximo de tres meses, a la vista de de la información remitida por el titular.

Con todo, cualquier autorización de emisión de gases de efecto invernadero queda extinguida en los siguientes supuestos:

a) Cierre de la instalación.

b) Falta de puesta en funcionamiento de la instalación transcurridos tres meses desde la fecha prevista de inicio de la actividad, salvo que haya causa justificada declarada por el órgano competente para otorgar la autorización.

c) En los supuestos de sanción.

d) La suspensión de la actividad de la instalación durante un plazo superior a un año.

Cada Comunidad Autónoma debe comunicar al Registro nacional de derechos de emisión las resoluciones de otorgamiento, modificación y extinción de las autorizaciones en el plazo de diez días desde la fecha de la resolución.

\section{b) Autorizaciones de emisión a una agrupación}

Las autorizaciones también pueden otorgarse a una agrupación de instalaciones, a cuyo efecto pueden formar parte de una agrupación las instalaciones que cumplan los siguientes requisitos:

- Que todas ellas lleven a cabo una actividad que produzca emisión de gases de efecto invernadero enumeradas en la Ley.

\footnotetext{
${ }^{10}$ Sin embargo la instalación podrá seguir funcionando de manera provisional, siempre que se haya establecido un sistema de seguimiento y notificación de las emisiones con arreglo a lo establecido en la Ley 1/2005 hasta que el órgano competente haya resuelto de forma expresa..
} 
- Que todas las instalaciones cuenten con una autorización individual de autorización de gases de efecto invernadero.

- Que designen un administrador fiduciario que tendrá las obligaciones que le atribuye la ley ${ }^{11}$.

- La agrupación debe disponer de una autorización otorgada de acuerdo con el procedimiento legalmente establecido a que se hace referencia más adelante.

- Cualquier modificación en la composición de la agrupación o de la identidad o facultades del administrador fiduciario debe ser comunicada al órgano competente para otorgar la autorización.

La autorización de la agrupación debe tener como contenido mínimo:

- La identificación del administrador fiduciario y la descripción de los poderes que le han sido atribuidos.

- La identificación de las instalaciones incluidas en la agrupación y de las autorizaciones de emisión con que aquellas cuenten.

- Enumeración de las obligaciones y limitaciones del administrador fiduciario en relación con la entrega de derechos de emisión y participación en el mercado.

- Plazo de vigencia de la autorización.

Los titulares que deseen formar una agrupación de instalaciones deben presentar en el Ministerio de Medio Ambiente una solicitud conjunta de autorización acompañada de la siguiente documentación:

- Acreditación de la identidad de las instalaciones y sus titulares.

- Periodo para el que se solicita la autorización de agrupación.

- Copia compulsada de la autorización de emisión de cada instalación.

${ }^{11} \mathrm{El}$ artículo 13 de la Ley 1/2005 establece las obligaciones del administrador fiduciario:

1 Los derechos de emisión correspondientes al total de derechos asignados a cada una de las instalaciones incluidas en la agrupación serán transferidos de la cuenta de haberes de la Administración General del Estado a la de la agrupación..

2 La energía anual de derechos de emisión en cantidad equivalente a la suma de emisiones verificadas de las instalaciones incluidas en la agrupación deberá efectuarse por el administrador fiduciario.

3 El administrador fiduciario no podrá transmitir derechos de emisión del titular cuyo informe no haya sido considerado conforme, de acuerdo con lo previsto en la propia Ley (art. 23). 
- Escritura pública de poder otorgado a un administrador fiduciario único $^{12}$.

- Declaración de que el administrador no se encuentre, en el momento de presentar la solicitud, inhabilitado conforme a lo dispuesto en la legislación mercantil.

Informe explicativo valorando la incidencia de la agrupación en el mercado exterior.

Respecto a procedimiento de otorgamiento, la autorización de agrupación de instalaciones será otorgada por el Consejo de Ministros ${ }^{13}$, previo informe de las Comunidades Autónomas en cuyos territorios se ubiquen las instalaciones solicitantes y del Servicio de defensa de la competencia.

Si la solicitud reúne los requisitos que exige la Ley ${ }^{14}$, se valorarán favorablemente sus efectos sobre la competencia, el mercado interior y el interés de los consumidores y se remite el expediente al órgano competente de la Comisión Europea que podrá, en un plazo de tres meses, rechazar motivadamente toda solicitud que no cumpla los requisitos exigido en la normativa comunitaria ${ }^{15}$.

Si la Comisión Europea rechaza la solicitud, el órgano competente solo puede autorizar la agrupación de instalaciones si aquella acepta las modificaciones propuestas.

La resolución debe dictarse en un plazo de seis meses desde la presentación de la solicitud, transcurrido dicho plazo sin haberse notificado resolución expresa, el interesado puede entender desestimada su solicitud por silencio administrativo.

\footnotetext{
${ }^{12}$ Mediante la cual se acredite su capacidad para cumplir con la obligación de entrega de derechos de emisión y se precise la relación entre todos los titulares de las instalaciones incluidas en la agrupación o el administrador.

${ }^{13}$ A propuesta de los ministerios de Medio Ambiente, de Hacienda, Industria y la Comisión de Políticas de cambio climático.

${ }^{14}$ En el artículo 9.1.

${ }^{15}$ En la Directiva 2003/87/CE.
} 
Con todo, la resolución que se adopte debe ser notificada al $\operatorname{Renade}^{16} \mathrm{y}$ a las Comunidades Autónomas afectadas.

\section{PLAN NACIONAL DE ASIGNACIÓN DE DERECHOS DE EMI- SIÓN}

El Plan nacional de asignación debe establecer para cada periodo de vigencia, el número total de derechos de emisión que está previsto asignar; el procedimiento de asignación, la cantidad de reducciones previsibles ${ }^{17}$ y el porcentaje de la asignación a cada instalación ${ }^{18}$. El Plan nacional debe basarse en criterios objetivos y transparentes, teniendo en cuenta las alegaciones formuladas en especial las que correspondan a los sectores de actividad incluidas en su ámbito de aplicación.

Es aprobado por el Gobierno mediante Real Decreto ${ }^{19}$, previo informe del Consejo Nacional del Clima $^{20}$ y de la Comisión de coordinación de políticas de cambio climático ${ }^{21}$.

La asignación de derechos para el primer periodo de tres años hasta comienzo de 2008 será gratuita ${ }^{22}$, a partir de esa fecha con el segundo Plan se asignarán de forma gratuita el noventa por ciento, asignando el resto en consideración a la necesaria competitividad de la industria nacional.

\footnotetext{
16 Registro nacional de derechos de emisión.

${ }^{17}$ Reducciones certificadas de emisión y unidades de reducción de emisiones que es previsible emplear.
}

${ }^{18}$ En el que se autoriza el uso de este tipo de créditos a su titular para cumplir, a lo cuatro meses siguientes de cada año, con la obligación de entrega de lo derechos de emisión en cantidad equivalente a las emisiones totales verificadas de la instalación en el año anterior.

${ }^{19}$ A propuesta de los ministros de Hacienda, Industria y Medio Ambiente.

${ }^{20}$ Que también participa en el seguimiento del Plan.

${ }^{21}$ El actual Plan Nacional entró en vigor el primero de enero de 2005 y tendrá una vigencia de tres años, el segundo Plan Nacional de asignación y los sucesivos tendrán una vigencia de cinco años cada uno.

${ }^{22}$ Salvo loo que la ley dispone respecto a los nuevos entrantes. 
La cantidad total de derechos que asigne el Plan se establecerá de acuerdo con la normativa comunitaria y en particular en función de:

- Los compromisos internacionales en materia de emisiones de gases de efecto invernadero asumidos por España.

- La contribución de las instalaciones sometidas a la Ley 1/2005 al total de emisiones nacionales.

- Las previsiones de emisión, incluidas las posibilidades técnicas y económicas de reducción de emisiones en todos los sectores.

- Las previsiones de apertura de nuevas instalaciones o ampliación de las existentes.

Los titulares de instalaciones deben solicitar al Ministerio de Medio Ambiente la asignación de derechos de emisión para el periodo de vigencia del Plan Nacional de asignación. Esta solicitud de be presentarse ante el organismo autonómico competente para tramitar la autorización de emisión de gases de efecto invernadero que la remitirá, en el plazo de diez días, al Ministerio de Medio Ambiente.

Esta solicitud debe presentarse doce meses antes del inicio de cada periodo de vigencia del Plan nacional de asignación ${ }^{23}$.

Cada solicitud debe venir acompañada de la documentación en la que consten los siguientes extremos:

- Acreditación del titular de la instalación y disponer de autorización de emisión de gases de efecto invernadero.

- Datos de la instalación, referidos a los tres años anteriores a la presentación de la solicitud sobre: acreditación de ser titular de la instalación y disponer de autorización de emisión y datos de la instalación, referidos a los tres años anteriores sobre emisión de los gases y consumo de combustible ${ }^{24}$.

\footnotetext{
${ }^{23}$ Las instalaciones que tengan la consideración de nuevos entrantes deben solicitar la asignación individualizada de derechos de emisión, una vez que dispongan de autorización de emisión de gases de efecto invernadero.

${ }^{24}$ Dice la Ley que no es necesario aportar los datos de emisiones verificadas que ya consten en el Renace. Por otra parte esta declaración es consecuente con el derecho de no aportación de documentación que ya conste a la Administración contenido en la Ley 30/1992 de Régimen Jurídico de las Administraciones Públicas y del Procedimiento Administrativo Común.
} 
- La estimación de la evolución en la instalación de la producción, los consumos de combustible y materias primas, así como de las emisiones de gases de efecto invernadero en cada periodo comprendido en el Plan nacional de emisiones.

La resolución de asignación de derechos de emisión corresponde al Consejo de Ministros una vez cumplimentado el trámite de información pública y previa consulta a la Comisión de coordinación de políticas de cambio climático. Esta resolución determinará la cantidad de derechos asignada a cada instalación durante el periodo de vigencia del Plan nacional. Transcurrido el plazo de tres meses sin haberse notificado resolución expresa, el interesado podrá entender desestimada su solicitud por silencio administrativo.

Además la resolución debe ser comunicada, en el plazo de diez días desde su adopción, al Renace y a las Comunidades Autónomas.

Las resoluciones sobre asignación individualizada de derechos de emisión serán accesibles al público, en los términos y con las limitaciones previstas en las normas reguladoras del derecho de acceso a la información en materia de Medio ambiente.

La metodología de asignación individual de derechos de emisión debe tener en cuenta la normativa comunitaria y en concreto los criterios siguientes:

- Que no produzca diferencias injustificadas entre diversos sectores de actividad.

- Que sea coherente con las posibilidades técnicas y económicas de reducción de cada sector.

- Las medidas de reducción adoptadas antes del establecimiento del mercado de derechos de emisión.

- Las previsiones de evolución de la producción.

\section{OBLIGACIONES DE INFORMACIÓN DE LAS EMISIONES}

El titular de la instalación debe remitir al órgano autonómico competente dentro de los dos primeros meses del año ${ }^{25} \mathrm{el}$ informe verificado sobre las

\footnotetext{
${ }^{25}$ Antes del 28 de febrero.
} 
emisiones del año precedente ajustado a lo exigido en la autorización. Este informe debe ser verificado por los organismos acreditados oficialmente.

Cuando la Comunidad Autónoma de su conformidad al informe verificado de la instalación procederá a inscribir el dato sobre emisiones del año precedente en la tabla d emisiones del Renade. Si el órgano autonómico discrepara del informe verificado, notifica al titular de la instalación estas discrepancias a fin de que se resuelvan y pueda considerarse satisfactorio el informe.

\section{REGISTRO NACIONAL DE DERECHOS DE EMISIÓN}

La Ley define el Registro nacional de derechos de emisión como el instrumento a través del cual se asegura la permanente actualización de la contabilidad relativa a los derechos de emisión.

Es un registro público adscrito al ministerio de medio ambiente que tiene por objeto la inscripción de todas las operaciones relativas a la expedición, titularidad, transmisión, transferencia, entrega, retirada y cancelación de derechos de emisión, además de la suspensión de la capacidad de transmitir derechos de emisión.

Esta materia se ha desarrollado por Real Decreto 1264/2005 de 21 de octubre regula la organización y funcionamiento del Registro nacional de derechos de emisión (Renade) ${ }^{26}$ que es el instrumento a través del cual se asegura la publicidad y permanente actualización de la titularidad y control de los derechos de emisión. Es renace forma parte del sistema comunitario de registros integrados regulado por el Reglamento (CE) no 2216/2004 por ello deberá estar conectado con el diario independiente de transacciones de la Convención Marco de las Naciones Unidas sobre cambio climático.

El objeto del Renade es la inscripción de la expedición, titularidad. transmisión, entrega, retirada, cancelación y transferencias de los derechos de emisión, así como la inscripción de la suspensión de la capacidad de transmitir derechos de emisión en los supuestos previstos en la normativa de aplicación. Además deben inscribirse en el Renade la expedición, titularidad transmisión, entrega retirada cancelación y trasferencias que tengan por objeto las demás

${ }^{26}$ BOE núm. 59 de 10.3.2005. 
unidades relevantes de cantidad asignada o, en su caso, de reducciones de emisión en cualquiera de la modalidades definidas por el Reglamento $\mathrm{n}^{\mathrm{o}}$ 2216/2004.

La oficina encargada del Renade tiene a su cargo las siguientes funciones:

- $\quad$ Gestión y mantenimiento del registro ${ }^{27}$.

- Facilitar al público el acceso a la información contenida en el registro, en los términos legales.

- Facilitar a los órganos competentes cuanta asistencia resulte necesaria para desempeño de las funciones que tengan encomendadas en relación con el registro.

- Cualquier otra función que le encomiende la normativa vigente.

\section{ESTRUCTURA DEL REGISTRO: LAS CUENTAS}

El Renade consta de cuentas separadas donde se inscriben los derechos de emisión, las operaciones de expedición, transferencia, entrega, retirada y cancelación.

De acuerdo con lo establecido en la normativa comunitaria ${ }^{28}$ el Renade contará al menos con las siguientes cuentas y tablas:

- Una cuenta de haberes de la que será titular la Administración General del Estado AGE, en la cual se inscriben todos los derechos de emisión que figuren en cada plan nacional de asignación ${ }^{29}$.

- Una cuenta de retirada y otra de cancelación, de las que será titular la AGE para los periodos de vigencia de cada plan nacional de asignación.

- Una cuenta de haberes por cada instalación que disponga de autorización de emisión de gases de efecto invernadero, a nombre de su titular.

${ }^{27}$ De conformidad con lo establecido en la Ley $1 / 2005$ de 9 de marzo y el Reglamento (CE) no $2216 / 2004$.

${ }^{28}$ Reglamento (CE) 2216/2004 de la Comisión de 21 de diciembre de 2004.

${ }^{29}$ De acuerdo con los establecido en el artículo 20.2 de la Ley $1 / 2005$. 
- Una cuenta de haberes por cada agrupación de instalaciones que disponga de autorización de agrupación, a nombre del administrador fiduciario autorizado.

- Una cuenta de haberes por cada persona física o jurídica con domicilio en territorio de la -Unión Europea que lo solicite.

- Una tabla de emisiones verificadas.

- Una tabla de entrega de derechos.

- Una tabla sobre estado de cumplimiento de la obligación de entrega anual de derechos de emisión de gases de efecto invernadero ${ }^{30}$.

El Renade debe mantener abiertas las siguientes cuentas:

a) Una cuenta por cada autorización de emisión de gases de efecto invernadero en vigor.

b) Una cuenta por cada agrupación de instalaciones autorizadas a nombre de su administrador fiduciario en tanto dicha autorización siga siendo válida.

c) Una cuenta de haberes, otra de retirada y otra de cancelación a nombre de la AGE.

Además de los titulares mencionados, también pueden ser titulares de cuenta, las personas físicas o jurídicas distintas de las enumeradas que sean parte en una transmisión de derechos y no dispongan de cuenta en otro registro nacional de emisión de un Estado miembros de la Unión Europea o en el registro de un tercer país con compromiso de reducción o limitación de emisiones que sea parte del protocolo de Kyoto o de la Convención marco de naciones Unidas sobre cambio climático.

Además cualquier persona física o jurídica podrá ser titular de una o más cuentas en el Renade ${ }^{31}$. Como límite numérico reglamentario queda prohibida la apertura de un número de cuentas superior a noventa y nueve a nombre de una misma persona.

Los titulares de las cuentas deben ser notificados por el Renade de la apertura, actualización o cierre, así como de cualquier otra circunstancia que pueda afectar a las cuentas o a la transmisibilidad de derechos.

\footnotetext{
${ }^{30}$ En lo términos establecidos en el artículo 55 del Reglamento (CE) 2216/2004.

${ }^{31}$ De acuerdo con lo establecido en la Ley 1/2005.
} 


\section{DINÁMICA REGISTRAL DE LAS CUENTAS DEL RENADE}

Pueden ser titulares de cuentas en el Renade:

- Los titulares de autorizaciones de emisión de gases de efecto invernadero.

- Los administradores fiduciarios de agrupaciones o instalaciones autorizadas.

- Cualquier otra persona de acuerdo con la Ley 1/2005.

La apertura de una cuenta requiere:

- Presentar en el Renade la solicitud de apertura cumplimentada y firmada.

- Con los datos que acrediten la identidad del solicitante o de sus representantes.

- El poder a favor de los representantes y la firma de un contrato en que se determinen los derechos y obligaciones de las partes de conformidad con lo que en cada momento determine la legislación aplicable.

El Renade abrirá la cuenta a favor del titular en el plazo de diez días desde la presentación de la solicitud.

El titular de cuenta debe notificar al Renade cualquier variación de afecte a la información de la cuenta contenida en el registro dentro de los diez días siguientes a que se hubiera producido la misma, estas comunicaciones obligan a registro a llevar a acabo las modificaciones registrales que correspondan en el plazo diez días.

Además los titulares de cuentas deben designar representantes autorizados en relación con cada cuenta y están obligados al cumplimiento estricto de las normas de organización y funcionamiento contenidas el Real Decreto $1264 / 2005^{32}$.

El cierre de cuentas de los titulares de instalaciones se lleva a cabo por el Renade, atendiendo a las instrucciones recibidas por el órgano administrativo

${ }^{32}$ Así como en el Reglamento CE 2216/2004 
competente en los supuestos de extinción de la autorización de emisión de gases de efecto invernadero o, en caso de cuentas a nombre de administrador fiduciario, por la extinción de la autorización de agrupación de instalaciones.

Cuando se constaten derechos de emisión inscritos en la cuenta afectada, el Renade requerirá al titular para que, de forma inmediata y fehaciente, facilite los datos de otra cuenta a la que transferir los derechos y si en el plazo de sesenta días el Renade no hubiese recibido dicha información , procederá al cierre de la cuenta, previa transferencia de los derechos a la cuenta de haberes de la Administración General del Estado.

Los titulares de cuenta pueden solicitar, en cualquier momento, el cierre de sus respectivas cuentas ${ }^{33}$, el Renade procederá al cierre de las cuentas en el plazo de diez días desde la recepción de la solicitud.

Cuando un cuenta presente saldo cero ${ }^{34}$ sin que se hayan consignado transacciones durante un periodo de doce meses, el registro debe notificar esta circunstancia al titular de la cuenta informándole de que procederá a su cierre en el plazo de sesenta días y de no recibir en dicho plazo una solicitud de mantenimiento el Renade procederá al cierre de la cuenta.

El Renade practica las inscripciones siguiendo el tradición principio registral que el primero en el tiempo es preferente en el derecho ${ }^{35}$ siguiendo el orden cronológico de las solicitudes recibidas. Las solicitudes de transferencia que se reciban antes serán preferentes sobre las que accedan con posterioridad, además una vez inscrita cualquier transferencia en las cuentas no podrá practicarse ninguna otra respecto de los mismos derechos de emisión que resulte incompatible con la anterior.

Las transferencias de cuentas del Renade se practican solo a instancia del titular de la cuenta en la que consten anotados los derechos as que afecten me-

\footnotetext{
${ }^{33}$ Excepto las que se refieran a autorizaciones de emisión, agrupación de instalaciones y las de haberes, retirada y cancelación a nombre de la AGE. El cierre de estas cuentas solo será posible por extinción de la autorización de emisión o por extinción de la autorización de agrupación de instalaciones ver artículo 8.3 R.D. 1264/2005.

${ }^{34}$ Excepto las mencionadas en el artículo 5.1 R.D. 1264/2005.

35 Prior in tempore potior in iure.
} 
diante la correspondiente solicitud ${ }^{36}$. Las transferencias no requieren el consentimiento del titular de la cuenta destinataria, sin perjuicio del ejercicio por parte de éste de las facultades que le correspondan sobre la gestión y administración de su cuenta, de acuerdo con la normativa aplicable. Con todo para la inscripción de la transmisión o de cualquier otra circunstancia que afecte a los derechos de emisión, será precisa su inscripción previa en la cuenta de haberes abierta por el transmitente.

La transmisión derechos de emisión tiene lugar en el momento de su inscripción en el Renade, una vez concluidos los procesos de validación por el Administrador central ${ }^{37}$. Siguiendo un principio registral el contenido del Renade se presume exacto y válido ${ }^{38}$ y producirá los efectos que corresponda mientras no se inscriba la declaración judicial de su inexactitud o nulidad. La inscripción no convalida los actos o contratos que sean nulos con arreglo a la ley, además el tercero que adquiera, a título oneroso, sin mala fe ni culpa grave de titular inscrito no estará sujeto a reivindicación teniendo el amparo de la publicidad del Renade.

El Renade es un registro de acceso público a los usuarios a través de su propia página WEB siendo accesible al público de manera transparente y organizada, la relativa a las cuentas, sus titulares, estado de cumplimiento, haberes y transacciones y porcentaje máximo de empleo de unidades procedentes de los mecanismos y condiciones establecido en la normativa comunitaria $^{39}$. Todo lo demás contenido en el Renade tienen la consideración de información confidencial a todos los efectos, incluyendo los haberes de todas las cuentas y todas las transferencias llevadas a cabo.

\footnotetext{
${ }^{36}$ Salvo las inscripciones que sean consecuencias de verificaciones registrales como establece el artículo 14.2 del R.D. 1264/2005.

${ }^{37}$ El artículo 14.3 del R.D. 1264/2005 dispone que todos los procesos relativos a cuentas y emisiones verificadas se darán por finalizados cuando el Diario independiente de transacciones comunitario haya notificado al Renade que no ha detectado discrepancia alguna en la propuesta enviada por éste y el Renade haya enviado a aquel la confirmación de actualización de los datos con arreglo a dicha propuesta.

${ }^{38}$ Presunción iuris tantum que admite prueba en contrario mediante el correspondiente procedimiento de impugnación.

${ }^{39}$ Anexo XVI del Reglamento CE 2216/2004.
} 
Esta información confidencial no puede ser utilizada sin el consentimiento previo del titular de la cuenta correspondiente, excepto cuando su uso sea en ejercicio de las funciones de supervisión de la autoridad judicial o administrativa competente para solicitarla o fuera necesario para la adecuada gestión y mantenimiento del registro, con arreglo a lo dispuesto en la normativa mencionada.

Entre las obligaciones del Renade se encuentran las siguientes:

a) Cumplir todas las resoluciones adoptadas por las autoridades judiciales que le sean notificadas incluyendo particularmente la de ejecución forzosa o medidas cautelares que recaigan sobre los derechos inscritos d emisión en el registro.

b) Atender las peticiones de información y de embargo que reciban de las autoridades administrativas competentes.

c) Conservar los datos relativos a todos los procesos y titulares de cuentas durante quince años o hasta que se hayan resuelto las cuestiones relacionadas que puedan afectarles.

\section{PROCEDIMIENTO REGISTRAL}

Los procesos relativos a los derechos de emisión, las emisiones verificadas y las cuentas deben completarse a través del Diario independiente de transacciones comunitario (DITC) ${ }^{40}$.

Antes de la ejecución de cualquier proceso y durante su transcurso el Renade velará por que se efectúen las verificaciones automáticas adecuadas para detectar, en la medida de los posible, las discrepancias que pudiesen existir antes de que se lleven a cabo verificaciones automáticas ${ }^{41}$.

\footnotetext{
${ }^{40}$ Hasta la creación del diario independiente de transacciones de la Convención Marco de Naciones Unidas sobre Cambio Climático y el establecimiento del enlace previsto en el artículo 7 del Reglamento CE 2216/2004 todos los procesos relativos a los derechos de emisión, las emisiones verificadas y las cuentas completarse mediante el intercambio de datos a través del diario independiente de transacciones comunitario (DITC).

${ }^{41}$ Por el DITC o el diario independiente de transacciones de la Comisión Marco de las Naciones Unidas sobre Cambio Climático.
} 
Los procesos relativos a cuentas y emisiones verificadas deben darse por finalizados cuando el DITC haya notificado al Renade, que no ha detectado discrepancia alguna en la propuesta enviada por éste ${ }^{42}$. Además, todos los procesos de transferencias en los que la cuenta de origen o la de destino estén abiertas en un registro de derechos de emisión distinto al previsto en la regulación ${ }^{43}$ deben darse por finalizados cuando el DITC haya notificado al Renade que no ha detectado discrepancia alguna en la propuesta enviada por el registro iniciador, y el registro receptor haya enviado al DITC la conformación de que ha actualizado sus datos con arreglo a la propuesta.

Los órganos competentes de las Comunidades Autónomas o, en su caso, el Ministerio de Medio Ambiente deben comunicar al Renade las resoluciones de otorgamiento, modificación y extinción de las autorizaciones de emisión de gases de efecto invernadero y de agrupación de instalaciones en el plazo de diez días desde la fecha en que fuesen dictadas, para ello pueden disponer de un acceso al registro a través del cual pueden suministrar la información prevista en el Reglamento 2216/2004.

\section{INSCRIPCIONES EN EL RENADE}

Las inscripciones en el Renade pueden ser de tres tipos: primera inscripción de derechos, inscripción de transmisiones de derechos e inscripción de transferencias.

\section{a) Primeras inscripciones}

Los derechos de emisión pueden tener origen en cualquiera de las causas que señala la Ley $1 / 2005^{44}$ y los que figuren en el Plan nacional de asignación

\footnotetext{
42 También deben quedar finalizados todos los procesos de transferencias entre cuentas cuando el DITC haya notificado al Renade que no ha detectado discrepancia alguna en la propuesta enviada por éste y, además el Renade haya enviado al DITC la confirmación de que ha actualizado sus datos con arreglo a dicha propuesta.

${ }^{43}$ En el Real Decreto 1264/2005.

44 Artículo 20.6 de la Ley 1/2005 Los derechos de emisión pueden tener su origen en:

a) El Plan nacional de asignación de España.

b) Un Plan nacional de asignación de otros Estado miembro de la Unión Europea.
} 
previstos para cada periodo o que resulten de la conversión de unidades de cantidad asignada serán expedidos e inscritos en la cuenta de haberes de la Administración General del Estado AGE antes del 28 de febrero del año inicial de vigencia de cada plan. El Renade asignará un código de identificación de la unidad exclusivo a cada derecho de emisión.

Los derechos que correspondan a cada titular de instalación serán transferidos de la cuenta de haberes de la AGE a la correspondiente cuenta de acuerdo con la distribución temporal establecida en la resolución de asignación ${ }^{45}$, a dicho efecto, el representante autorizado de la cuenta de haberes de la AGE comunicará al Renade los datos necesarios para poder llevar a cabo las correspondientes transferencias.

Los derechos asignados a nuevos entrantes y a instalaciones cuya ampliación o entrada en funcionamiento haya quedado prevista ene. Plan nacional de asignación inicial también serán transferidos de la cuenta de haberes de la AGE a la del titular de la instalación, de conformidad con las instrucciones recibidas del representante autorizado de la cuenta de haberes de la AGE.

Si una vez inscritos los derechos de emisión en la cuenta de haberes de la AGE hubieran tenido lugar correcciones en el plan nacional de asignación de las que resultara una reducción de la cantidad total de derechos expedidos, el Renade deberá proceder a:

c) Un tercer país con compromiso de reducción o limitación de emisiones que sea parte en el Protocolo de Kyoto o la Convención de Naciones Unidas de Cambio Climático, siempre que haya previo reconocimiento en un instrumento internaciones.

d) Una reducción certificada de emisión o una unidad de reducción de emisiones procedentes de los mecanismos de desarrollo limpio o de aplicación conjunta que sea expedida de conformidad con lo establecido en la Convención Marco de Naciones Unidas sobre el Cambio Climático, el Protocolo de Kyoto y su normativa de desarrollo sea reconocida a los efectos de cumplir con la obligación de entregar información sobre el total de emisiones. El reconocimiento podrá tener lugar siempre que:

-) No hayan sido generadas por instalaciones nucleares.

- No hayan sido generadas por actividades de uso de la tierra, cambio de uso de la tierra o selvicultura,

a. En el caso de proceder de proyectos de producción de energía hidroeléctrica con una capacidad superior los $20 \mathrm{MW}$, que dichos proyectos sean conformes con los criterios y directrices pertinentes aprobados por la Comisión mundial de presas.

${ }^{45}$ Referida en el artículo 19.5 de la Ley 1/2005. 
- La transferencia del número de derechos de emisión que determine la autoridad competente desde las cuentas de haberes afectadas a la cuenta de cancelación de la AGE.

- A la conversión de los derechos de emisión que especifique el órgano competente de la AGE en unidades de cantidad asignada.

\section{b) Inscripción de las transmisiones}

La inscripción de las transmisiones entre las cuentas se llevará acabo según las instrucciones recibidas de los correspondientes titulares de cuenta, a tal fin, las solicitudes de transferencia deberán adecuarse a los requisitos establecidos en el Reglamento CE 2216/2004, sin embargo en el caso de transmisión de derechos de emisión en los que la cuenta de origen o la de destino estén abiertas en un registro de derechos que se a diferente del previsto en el Real Decreto 1264/2005, la inscripción de la transmisión deberá contar con el consentimiento del registro receptor de los derechos y la conformidad del administrador de DITC ${ }^{46}$.

\section{c) Inscripción de las trasferencias}

Las transferencias derivadas del cumplimiento de la entrega ${ }^{47}$ deben ser reflejadas por el Renade en las tablas habilitadas al efecto. La entrega de derechos correspondientes a las emisiones verificadas tiene efecto por solicitud del titular de la cuenta que implica también solicitud de anotación del hecho en la tabla de entrega ${ }^{48}$ en la que la Comunidad Autónoma inscribirá los datos sobre emisiones del año precedente ${ }^{49}$, además el 30 de junio de cada año el Renade deberá cancelar aquellos derechos de emisión que hayan sido objeto de entrega y consten anotados en la cuenta de haberes de la AGE, me-

${ }^{46}$ De acuerdo con lo previsto en el Reglamento CE 2216/2004.

${ }^{47}$ Obligación establecida en el artículo 4.2 f de la Ley $1 / 2005$.

${ }^{48}$ De acuerdo con lo establecido en el reglamento CE 2216/2004 el Renade debe comunicar a los órganos competentes el cuadro del estado de cumplimiento elaborado así como todas sus modificaciones.

${ }^{49}$ Verificadas antes de 31 de marzo de cada año. 
diante la transferencia de dichos derechos a la cuenta de retirada ${ }^{50}$. En cualquier caso el Renade procederá, previa petición del titular de la cuenta, a la cancelación de los derechos de emisión indicados por éste, mediante la transferencia de éstos a la correspondiente cuenta de cancelación, además los derechos de emisión anotados en la cuenta de cancelación no pueden ser transferidos a ninguna otra cuenta de este Renade ni a cuentas de otros registros especiales.

\section{d) Suspensión de la capacidad de transmitir y expedición de derechos en ca- so de fuerza mayor}

El Renade deberá inscribir, a petición de la Administración competente, la suspensión de la capacidad de transmitir derechos del titular de cuenta en los casos siguientes:

- Cuando no hayan sido anotadas en la tabla de emisiones verificadas los datos correspondientes a la instalación dentro del plazo establecido al efecto.

- Cuando hayan sido detectadas irregularidades por el administración central del DITC.

La inscripción de esta suspensión no impedirá la entrega de derechos de emisión ni su cancelación o sustitución.

Los derechos de emisión asignados para casos de fuerza mayor, de acuerdo con lo establecido en la Ley $1 / 2005^{51}$ no son transmisibles si bien serán objeto de inscripción, entrega y cancelación en el registro. Los derechos de emisión para casos de fuerza mayor serán expedidos por el Renade, cuando así lo ordene el órgano competente, a la cuenta de haberes de la AGE, asignándoles un código de identificación de la unidad exclusivo a cada derecho, además el Renade anotará el número de estos derechos en las secciones de la tabla de entrega de derechos de emisión reservadas a las instalaciones y los años que hayan recibido la autorización.

\footnotetext{
${ }^{50}$ Sin embargo a partir del 30 de junio de 2009, la cancelación de los derechos se llevará a cabo, previa instrucción del correspondiente procedimiento administrativo.

El 1 de mayo de los años 2008, 2013 y primer año de cada periodo de cinco años subsiguientes, el Renade, previa instrucción del órgano competente de la AGE, efectuará la cancelación de los derechos de emisión creados por el plan nacional de asignación del periodo inmediatamente anterior.

${ }^{51}$ Disposición transitoria sexta.
} 
Con todo cuando el administrador central designado por la Comisión Europea detecte irregularidades en relación con operaciones de transferencia de derechos de emisión e informe de ellos al Renade, éste deberá suspender cautelarmente la inscripción de las operaciones afectadas y de cualesquiera otras en que estén implicados los correspondiente derechos de emisión hasta que no se resuelvan las irregularidades detectadas.

\section{RÉGIMEN SANCIONADOR}

Las infracciones se califican según su gravedad en muy graves, graves y leves.

Se consideran infracciones muy graves las siguientes:

- Ejercer la actividad sin la preceptiva autorización.

- Incumplir la obligación de informar sobre la modificación del carácter, funcionamiento o tamaño de la instalación siempre que ello suponga alteraciones significativas en los datos de emisión o requiera cambios en la metodología aplicable para cumplir las obligaciones legales de seguimiento.

- No presentar el informe anual.

- Ocultar o alterar intencionadamente la información exigida.

- Incumplir la obligación de entregar derechos.

- Impedir el acceso del verificador a los emplazamientos de la instalación en los supuestos en que se halle legalmente facultado.

- No aportar la información necesaria para el procedimiento de verificación.

Son infracciones graves:

- Ocultar o alterar intencionadamente la información exigida.

- Incumplir la obligación de informar sobre la modificación de la identidad o el domicilio del titular.

- Incumplir las condiciones de seguimiento de las emisiones establecidas en la autorización cuando de dicho incumplimiento se deriven alteraciones en los datos de emisiones.

- Incumplir las normas reguladoras de los informes anuales verificados, siempre que ello implique alteración de los datos de emisiones. 
Son infracciones leves:

- Incumplir las condiciones de seguimiento de las emisiones establecidas en la autorización cuando de dicho incumplimiento se deriven alteraciones en los datos de emisiones.

- Incumplir las normas reguladoras de los informes anuales verificados, siempre que no implique alteración de los datos de emisiones.

- Incumplir cualesquiera otras obligaciones legales si ello no estuviera tipificado como infracción muy grave o grave.

Las sanciones establecidas en la Ley son las siguientes:

a) Para infracciones muy graves:

- Multa de 50.001 hasta dos millones de euros.

- Clausura temporal, total o parcial, de las instalaciones por un periodo máximo de dos años.

- Inhabilitación para ejercicio de las funciones de administrador fiduciario por un periodo no superior a dos años.

- Extinción o suspensión de autorizaciones por periodo máximo de dos años.

- En los casos de incumplimiento de entrega de derechos multa de cien euros por cada tonelada emitida en exceso y la publicación de las sanciones firmes (identidad del sancionado y el carácter de la infracción). Además, el pago de la multa no exime al titular de entregar una cantidad de derechos de emisión equivalente a la de las emisiones en exceso, en el momento de entregar los derechos de emisión correspondientes al año natural siguiente a la comisión de la infracción.

b) Para infracciones graves:

- Multa de 10.001 a cincuenta mil euros

- Suspensión de la autorización por un periodo máximo de un año.

c) Para infracciones leves:

- Multa de hasta diez mil euros.

En caso de agrupación de instalaciones, cuando se incurra en infracciones sobre incumplimiento de obligaciones de entregar derechos, el administrador fiduciario responderá directamente del pago de la sanción pecuniaria que se pudiera imponer, además responderá subsidiariamente del pago de la citada sanción los titulares de instalaciones, en proporción a las emisiones realizadas por sus respectivas instalaciones con respecto al total de las emitidas por el conjunto de la agrupación durante el periodo de vigencia del Plan nacional de asignación. 
En la imposición de sanciones deberá mantenerse la debida adecuación entre la gravedad del hecho constitutivo de la infracción y la sanción aplicada, con especial consideración a los siguientes criterios:

- Existencia de intencionalidad.

- Reincidencia por emisión de más de una infracción tipificada en esta ley, cuando así haya sido declarado por Resolución firme.

- El beneficio obtenido por la comisión de infracción.

- La diferencia entre las emisiones reales y las notificadas.

Todos estos criterios deberán tenerse en cuenta para graduar la sanción que se imponga dentro del intervalo correspondiente a cada tipo de infracción, además la infracciones granes no darán lugar a suspensiones de autorización si se hubiera procedido a la subsanación de la infracción por propia iniciativa. En todo caso la clausura temporal, total o parcial de instalaciones deberá acordarse sin perjuicio del pago del salario o de indemnizaciones a los trabajadores que procedan y de las medidas que puedan arbitrarse para su garantía. Con todo cuando la cuantía de la multa resulte inferior al beneficio obtenido por la comisión de la infracción, su importe podrá ser aumentado hasta el doble de dicho beneficio.

La ley también ha previsto una serie de medidas de aplicación provisional, de manera que cuando se hubiera iniciado un procedimiento sancionador por infracción muy grave o grave y si fuera necesario para asegurar la eficacia de la resolución, el órgano competente para sancionar podrá acordar alguna de las siguientes medidas provisionales:

a) Clausura temporal, parcial o total, de instalaciones únicamente cuando se trate de procedimientos incoados por infracciones muy graves.

b) Precintado de aparatos o equipos.

c) Suspensión temporal de la autorización de emisión de gases de efecto invernadero.

d) Suspensión del acceso al mercado de derechos de emisión.

El ejercicio de la potestad sancionadora corresponde a las Comunidades Autónomas salvo casos de infracciones muy graves por ocultación de información o incumplimiento de obligación de entrega de derechos en agrupación de instalaciones cuya competencia corresponde al Consejo de Ministros.

Además la Ley establece que el contenido de la autorización de emisión de gases de efecto invernadero podrá incorporarse a la autorización ambien- 
tal integrada ${ }^{52}$, en las condiciones que determine cada Comunidad Autónoma afectada.

Con todo la Ley 1/2005 creó una comisión para ejercer como autoridad nacional para los mecanismos basados en el Protocolo de Kioto y concretamente las siguientes funciones:

Emitir informes preceptivos sobre participación en proyectos de desarrollo limpio y aplicación conjunta.

Proponer al Consejo de Ministros el reconocimiento de unidades de reducción de emisiones o reducciones certificadas de emisiones como derechos de emisión válidos.

Actuar como punto focal de España en la relación con la autoridad nacional designada por otros países para promoción y ejecución de proyectos de desarrollo limpio y aplicación conjunta.

Elevar a la Comisión Delegada del Gobierno para asuntos económicos y a la comisión de coordinación de políticas de cambio climático un informe anual sobre las actuaciones llevadas a cabo durante el año anterior.

Esta autoridad nacional tiene el mandato legal de promover convenios de colaboración con las Comunidades Autónomas para fomentar y facilitar el desarrollo de los compromisos de los Protocolos de Kyoto y además en las Comunidades Autónomas podrán crearse centros que colaboren con la autoridad nacional.

\section{EPÍLOGO}

La regulación de los diversos aspectos del derecho de emisión de gases de efecto invernadero a tenido lugar en nuestro ordenamiento interno por transposición de la Directiva comunitaria y supone un avance en la concepción de estos derechos administrativos subjetivos de segunda generación que vienen configurándose en varias ramas del derecho público español singularmente en Derecho medio ambiental. Esta nueva regulación puede servir además pa-

\footnotetext{
${ }^{52}$ Regulada por la Ley 16/2002 de 1 de julio de prevención y control integrado de la contaminación.
} 
ra iluminar la configuración de derechos subjetivos de este tipo en otros ámbitos toda vez que el sistema se ha completado con un mecanismo registral que además puede por sí mismo dar mucha luz para interpretar muchos aspectos de la mecánica de los registros administrativos que últimamente se han multiplicado en ámbitos diversos como herramienta para llevar a cabo un control estatal de actividades de competencia autonómica pero de las que la administración estatal debe responder en algún ámbito supranacional. La regulación del funcionamiento del Registro nacional de derechos de emisión (Renade) supone un notable avance en el sistema regulador de estos derechos cuya interacción en el mercado supone la actuación de la administración estatal y las diferentes administraciones autonómicas con lo cual quedan pendientes al igual que en muchos otros ámbitos del ordenamiento en que confluyen competencias y funciones de administraciones diferentes, la necesidad de que se lleve a cabo de manera más favorable a los ciudadanos aunque ello precise de la coordinación de ambos escalones de administración. 